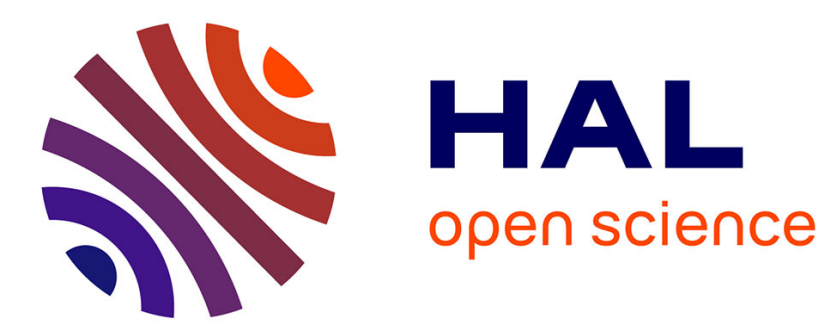

\title{
Synergistic and antagonistic effects in flame retardancy of an intumescent epoxy resin
}

Caroline Gérard, Gaelle Fontaine, Serge Bourbigot

\section{To cite this version:}

Caroline Gérard, Gaelle Fontaine, Serge Bourbigot. Synergistic and antagonistic effects in flame retardancy of an intumescent epoxy resin. Polymers for Advanced Technologies, 2011, 22 (7), pp.1085. 10.1002/pat.1996 . hal-00655428

\section{HAL Id: hal-00655428 \\ https://hal.science/hal-00655428}

Submitted on 29 Dec 2011

HAL is a multi-disciplinary open access archive for the deposit and dissemination of scientific research documents, whether they are published or not. The documents may come from teaching and research institutions in France or abroad, or from public or private research centers.
L'archive ouverte pluridisciplinaire HAL, est destinée au dépôt et à la diffusion de documents scientifiques de niveau recherche, publiés ou non, émanant des établissements d'enseignement et de recherche français ou étrangers, des laboratoires publics ou privés. 


\section{Synergistic and antagonistic effects in flame retardancy of an intumescent epoxy resin}

\begin{tabular}{|r|l|}
\hline Journal: & Polymers for Advanced Technologies \\
\hline Manuscript ID: & PAT-10-581.R2 \\
\hline Wiley - Manuscript type: & Special Issue: Research Article \\
\hline Date Submitted by the \\
Author: & 25-Mar-2011 \\
\hline Complete List of Authors: & $\begin{array}{l}\text { Gérard, Caroline; ENSCL, UMET } \\
\text { Fontaine, Gaelle; ENSCL, UMET } \\
\text { Bourbigot, Serge; ENSCL, PERF/LSPES }\end{array}$ \\
\hline Keywords: & $\begin{array}{l}\text { Epoxy, Fire Retardancy, Ammonium Polyphosphate, POSS, Carbon } \\
\text { Nanotubes }\end{array}$ \\
\hline
\end{tabular}




\begin{abstract}
Phosphorus-based products are able to strongly reduce the flammability of epoxy resins. In order to further improve their fire behaviour, combinations between a conventional flame-retardant (ammonium polyphosphate, APP) and two other particles have been investigated. The partial substitution of APP by carbon nanotubes (CNT) reveals an antagonism between these two compounds in terms of heat release rate measured by mass-loss calorimetry. On the contrary, the combination between octamethyl oligomeric silsesquioxane (OMPOSS) leads to a huge synergistic effect. These effects are mainly attributed to the char structures. Furthermore, the two systems were studied by thermogravimetric analysis (TGA) and they exhibit modifications of the degradation temperatures. The existence of different stabilization effects was also revealed.
\end{abstract}

KEYWORDS: Epoxy, Fire Retardancy, Ammonium Polyphosphate, POSS, Carbon Nanotubes

\title{
INTRODUCTION
}

Epoxy resins have many advantages for industrial applications. However, one of their main drawbacks is their poor resistance to fire. In order to limit this drawback, the use of phosphoruscontaining flame retardants is recognized as very effective ${ }^{[1]}$. They offer an alternative to halogenbased flame retardants and are particularly efficient in epoxy resins ${ }^{[2]}$. Zammarano et al ${ }^{[3]}$ reported the efficiency of ammonium polyphosphate in an epoxy resin at 5wt.\% loading: $80 \%$ decrease of the peak of heat release rate (pHRR) was observed by cone-calorimetry. In order to further enhance the reaction to fire of polymers filled with phosphorus-based compounds, our goal is to examine potential synergies between 'conventional phosphorus-based flame-retardants' and nanofillers. Fontaine et al. ${ }^{[4]}$ have shown the interest of the combination between APP, melamine and layered silicates (Cloisite 30B) in polylactide (PLA). Combining APP and melamine together already leads to 87\% pHRR decrease with 30wt.\% filler content. Further incorporation of a small amount of Cloisite 30B leads to a synergistic effect: the material exhibits a non-burning behaviour. Vannier et al. ${ }^{[5]}$ reported another synergy between OctamethylPOSS (OMPOSS) and zinc phosphinate in polyethylene terephtalate (PET). Polyhedral oligomeric silsesquioxanes (POSS) are hybrid molecules having a cage-like structure. The frame of the cage is made of silicon and oxygen in the ratio 1/1.5 and organic moieties are linked to its corners. In the present case, these are non-reactive methyl groups. The use of zinc phosphinate at 20wt.\% loading alone in PET decreases the pHRR by 30\%. Partial substitution by OMPOSS (2wt.\%) leads to a $65 \%$ decrease compared to virgin PET. This synergy is also observed by measuring the limiting oxygen index (LOI) of the materials. Considering epoxy systems, different groups have studied the effects of phosphorus-based flame-retardants in combination with organoclays ${ }^{[6-8]}$. No significant synergy has been discovered in such systems. Wang et al. ${ }^{[9]}$ have recently reported the positive interaction between octavinyl polyoligomeric silsesquioxane (OVPOSS) and a phosphorous-

\footnotetext{
*Correspondence to : G.Fontaine, ENSCL Laboratoire UMET, BP 90108, 59652 Villeneuve d'Ascq Cedex - France.

E-mail : Gaelle.Fontaine@ensc-lille.fr
} 
modified epoxy resin when studied by Pyrolysis Combustion Flow Calorimetry (PCFC): incorporation of $3 \mathrm{wt} . \%$ OVPOSS in the phosphorus-based resin decreases the pHRR by $45 \%$. Taking into account these results and based on the experience of our group (see e.g. ${ }^{[10,11]}$ ), we explored the possibility to enhance the reaction to fire of an epoxy resin by combining ammonium polyphosphate with other particles. The first one is carbon nanotubes. They have proven their benefit as flame retardants in various polymers ${ }^{[12-14]}$. They have also been widely incorporated in epoxy resins, mostly for their mechanical and electrical properties ${ }^{[15]}$. However, their efficiency as flame-retardants in epoxy is still discussed ${ }^{[16,17]}$ : they contributed to enhance the reaction to fire of epoxy systems in special cases (chemical modification and incorporation in the epoxy via sol-gel method or testing by conecalorimetry under nitrogen). The second particle combined with APP is OMPOSS (Octamethyl Polyhedral Oligomeric Silsesquioxane). Different varieties of POSS have been successfully used as flame-retardants in polymers ${ }^{[5,12]}$. Some of them have already been used in epoxies for this purpose ${ }^{[18,}$ 19]. In particular, Franchini et al. ${ }^{[20]}$ achieved a $40 \%$ pHRR decrease for an epoxy containing glycidoxypropyl-heptaphenyl POSS.

This paper investigates the potential synergistic effects of CNT and OMPOSS with APP on the flammability of a DGEBA epoxy resin. The fire behaviour will be evaluated by mass-loss calorimetry and PCFC. The thermal stability will be also examined by thermogravimetric analysis (TGA).

\section{EXPERIMENTAL}

\section{Materials}

Unless otherwise stated, all materials were obtained from commercial suppliers and used without further purification. Epoxy prepolymer (Bisphenol-A diglycidylether, Epoxy Equivalent Weight=172-176) and the hardener diethylenetriamine (DETA, 99\%) were supplied by Sigma-Aldrich. OMPOSS were purchased from Hybrid Plastics (MS0830, >97\% purity). Carbon nanotubes (CNT) were supplied by Nanocyl (Nanocyl 7000, 90\% purity). Ammonium polyphosphate (APP) was supplied by Clariant (AP422). Epoxy prepolymer was heated at $50^{\circ} \mathrm{C}$ for $24 \mathrm{~h}$ in order to avoid crystallization before use.

\section{Processing}

Fillers were mechanically mixed with epoxy prepolymer at $1600 \mathrm{rpm}$ for $20 \mathrm{~min}$ at room temperature (stirrer 94412 from Fischer Scientific). The stirrer was equipped with a disk-shaped tool and the mixing was carried out in $250 \mathrm{~mL}$ Nalgene containers. Batches of $80 \mathrm{~g}$ were prepared. The mixture was then sonicated for $1 \mathrm{~h}\left(100 \mathrm{~W}, 50 \mathrm{kHz}, 50^{\circ} \mathrm{C}\right)$ in a heated ultrasonic bath. After cooling down at room temperature, the amine hardener was mechanically incorporated in the mixture at 200 rpm for $5 \mathrm{~min}$ with the same stirrer as in the initial step. The mixture was then poured into aluminium moulds coated with a silicon-based demoulding agent and degassed at room temperature for 10min. The samples were then cured in a ventilated oven according to the following schedule: $30 \mathrm{~min}$ at $30^{\circ} \mathrm{C}$, $30 \mathrm{~min}$ at $40^{\circ} \mathrm{C}$ and $1 \mathrm{~h}$ at $50^{\circ} \mathrm{C}$. The compositions of the formulations used in this work are described in 
Table 1 . The prepolymer and the hardener are in stoichiometric ratio.

\section{Fire testing}

The Fire Testing Technology Mass Loss Calorimeter was used to perform measurements on samples following the procedure defined in ASTM E 906. However, because of the limited availability of the materials, the size of the specimens was reduced. Our procedure involved exposing specimens having a disk shape with a $77 \mathrm{~mm}$ diameter and a $5 \mathrm{~mm}$ thickness in horizontal orientation. Specimens were wrapped in aluminium foil leaving the upper surface exposed to the heater and placed on a ceramic backing board at a distance of $25 \mathrm{~mm}$ from cone base. External heat flux of $35 \mathrm{~kW} / \mathrm{m}^{2}$ was used for running the experiments. This flux corresponds to common heat flux in a mild fire scenario $^{[21]}$. When measured at $35 \mathrm{~kW} / \mathrm{m}^{2}$, heat release rate (HRR) is reproducible to within $10 \%$. Minimum three tests were carried out on each material.

The fire-retardant capability for limiting the release of combustible products was evaluated with a pyrolysis combustion flow calorimeter (PCFC) supplied by Fire Testing Technology Ltd and following the procedure defined in ASTM D7309. Samples about 5mg were placed in open alumina pans and were degraded in a nitrogen atmosphere at a heating rate of $1{ }^{\circ} \mathrm{C} / \mathrm{s}$ and a nitrogen flow of $80 \mathrm{cc} / \mathrm{min}$. The decomposition gases were then burnt in a nitrogen/oxygen mixture $(80 \mathrm{cc} / \mathrm{min}$ and $20 \mathrm{cc} / \mathrm{min}$ respectively) and the heat release rate was recorded as a function of temperature. Samples were weighed before the experiment and the heat release rate is normalized by this initial weight.

\section{Thermal stability}

Thermogravimetric analyses (TGA) were carried out at a heating rate of $10^{\circ} \mathrm{C} / \mathrm{min}$ in synthetic air (flow rate: $50 \mathrm{~mL} / \mathrm{min}$, Air Liquide grade), using a Setaram TG 92 microbalance. The samples were ground in liquid nitrogen in an ultra centrifuge mill to produce a powder $(500 \mu \mathrm{m}$ as average particle size). The samples $(10 \mathrm{mg})$ were placed in open vitreous silica pans (covered with gold in order to avoid reactions between pans and APP). The precision of the temperature measurements was $1.5^{\circ} \mathrm{C}$ over the whole range of temperature $\left(20-800^{\circ} \mathrm{C}\right)$.

Interactions between the compounds of a formulation can be revealed by comparing the experimental TG curve with a "calculated" TG curve $\left(\mathrm{W}_{\text {calc }}\right)$ obtained by linear combination of the TG curves of the formulation ingredients weighted by their contents.

$$
W_{\text {calo }}(T)=\sum_{i=1}^{n} x_{i} W_{i}(T)
$$

where $x_{i}$ is the content of compound $\mathrm{i}$ and $W i$ is TG curve of the compound $i$.

The $\Delta \mathrm{W}$ curve is calculated by subtracting the experimental curve from the calculated curve. Every positive interaction (stabilisation of the system compared to the theoretical value) is then shown by a positive value of the curve $(\Delta \mathrm{W}>0)$ and every negative interaction (destabilisation) by a negative value of the curve $(\Delta \mathrm{W}<0)$.

\section{RESULTS AND DISCUSSION Mass-loss calorimeter}

HRR as a function of time of virgin epoxy and of the fire-retardant formulations are presented in Figure 1. The incorporation of 5wt. $\%$ APP in epoxy leads to a 50\% decrease of pHRR. OMPOSS have also been incorporated in the resin and its pHRR is decreased by $46 \%$. When combining APP and OMPOSS, a synergistic effect providing a 68\% decrease of pHRR is shown. On the contrary, the combination between APP and CNT leads to an antagonism since only a $28 \%$ pHRR decrease is observed.

The time to ignition is also affected by the incorporation of flame retardants: compared to virgin epoxy, the ignition occurs earlier for each filled formulation (Table 2). It is similar for Epoxy/APP and Epoxy/APP/OMPOSS (75s compared to 94s for virgin epoxy) and slightly shorter for 
Epoxy/OMPOSS (67s). The time to ignition is drastically shortened (55s) for Epoxy/APP/CNT compared to virgin epoxy. It is noteworthy that in the particular case of polymers containing CNT, this behaviour has already been commented ${ }^{[13]}$. It originates from two different possible phenomena: the thermal conductivity is likely enhanced by the presence of CNT. Furthermore, the black colour of the sample containing CNT suggest the possibility of an increased absorption of the radiant heat in the mass-loss calorimeter (the other samples are either white or translucent). Therefore, the sample containing CNT can absorb more quickly the radiant heat, leading to accumulation of heat at the surface and then to a faster ignition.

Regarding the total heat release (THR) (Table 2), it is decreased by $20 \%$ when APP or OMPOSS are incorporated alone in the resin. The combination between APP and CNT leaves the THR almost unmodified (-4\%), confirming the antagonism observed on the pHRR. Finally, the value for APP/POSS formulation cannot be used: this sample produces a very stable and intumescent char that hinders the ventilation in the mass-loss chimney and causes a heat accumulation in the system (HRR values cannot come back to zero avoiding the calculation of THR).

The morphology of the residues after burning should give clues on the fire retardant behaviour. While virgin epoxy leaves almost no residue, incorporation of 5\%OMPOSS produces a fragile residue made of very thin gray-white layers (probably constituted of silica coming from the degradation of POSS $^{[22]}$ ) (Figure 2). APP-based formulations provide an intumescent phenomenon (formation of an expanded char). However, the addition of OMPOSS or CNT in combination with APP drastically changes the final residue. The sample containing 5\%APP produces a high char (height $=63 \mathrm{~mm}$ compared to $5 \mathrm{~mm}$ before the experiment, i.e. $1160 \%$ expansion), with important voids inside. In this case, the char structure is not resistant enough: cracks at different locations are formed probably because of the evolving gas flow. When APP is partly substituted by OMPOSS, the residue is smaller (height $=41 \mathrm{~mm}$ i.e. $720 \%$ expansion). In this case, the char seems to be more resistant and only small cracks can be distinguished in the middle of small bubbles distribution. Furthermore, one can easily distinguish two areas: the lower area is black whereas the upper one is filled with bubbles and has a metallic appearance. In the particular case of POSS having organic parts of low molecular weight, Fina et al. have shown that sublimation occurs during thermal degradation in addition to the formation of the silica layer ${ }^{[22]}$. One may therefore suggest that the POSS sublimates during the polymer burning but is trapped in the residue and recondenses. This phenomenon would explain the presence of the upper area full of bubbles and the black area may be mainly constituted of residual polymer. The formation of metallic carbon during carbonization has already been observed and may be the cause of the metallic glints of the upper area. Finally, when CNT partly substitutes APP, the residue is slightly smaller (height $=35 \mathrm{~mm}$ i.e. $600 \%$ expansion). Very large and easily breakable cells are created. Furthermore, very small holes can be distinguished at the top surface of the specimen.

Weight loss of the samples was also recorded during the experiments (Figure 3 and Table 2). Virgin epoxy degrades in a fast single step. The sample containing 5\%OMPOSS degrades quicker than virgin epoxy between 100 and 130s but a stabilization occurs thereafter until 450s, and its residual weight becomes higher than that of virgin epoxy until 300s. This is consistent with the generally accepted mode of action of POSS: during the burning of the sample, a ceramic layer is formed which protects the material from further degradation ${ }^{[18-20,22]}$. In the case of epoxy containing OMPOSS, the layer is fragile and it is progressively swept away by convection effect in the experimental apparatus. This drawback is responsible for the continuous mass loss up to the end of the test. The incorporation of APP (5wt.\%) in epoxy clearly increases the residual weight. The initial mass loss (before 110s) is similar for all specimens but it is reduced thereafter for Epoxy/APP. The mass of the final residue is relatively high (19wt.\%) for this formulation, showing further that the produced intumescent char is able to limit the polymer degradation and subsequently its weight loss. Similar observations can be done for the combination between APP and POSS. However, it is noteworthy that the main degradation step is delayed compared to APP alone (25s shifting towards higher times). On the contrary, the results obtained for the combination between APP and CNT confirm the negative interaction between these two particles. The degradation begins earlier compared to virgin epoxy and 
so does the main degradation step. This result supports the aforementioned hypothesis concerning the possibly modified heat absorption for samples containing CNT. The final residue is higher than for non-filled epoxy (7.5wt.\%), but it consists mainly of a hollow structure providing limited protection.

\section{Pyrolysis Combustion Flow Calorimeter (PCFC)}

The amount of combustible compounds and the temperatures at which they are released can be evaluated by PCFC. This is very helpful for determining if a flame retardant modifies the degradation pathway towards less flammable species or acts through a condensed phase mechanism. Only one main step is observed for all samples (See supplementary information). The curves are very similar for virgin epoxy and Epoxy/OMPOSS. The pHRR occurs at $357^{\circ} \mathrm{C}$ and $355^{\circ} \mathrm{C}$ and reaches respectively 428 and $419 \mathrm{~W} / \mathrm{g}$. Incorporation of APP alone slightly reduces the pHRR $(381 \mathrm{~W} / \mathrm{g},-11 \%)$, and the degradation occurs at lower temperatures $\left(337^{\circ} \mathrm{C}\right)$ (Table 3$)$. The combination between APP and POSS does not improve the reduction observed with APP alone, and moreover, the pHRR reaches $414 \mathrm{~W} / \mathrm{g}$ for APP/POSS (3\% reduction compared to virgin epoxy) at the same temperature as APP alone. Finally, the negative aspects of the partial substitution of APP by CNT are once more observed: the pHRR reaches $410 \mathrm{~W} / \mathrm{g}(-4 \%)$ and occurs at the lowest temperature among all samples: $318^{\circ} \mathrm{C}$.

Therefore, the amounts of fuels released during these experiments are slightly reduced when APP is incorporated in virgin epoxy. The partial substitution of APP by OMPOSS, which exhibit an important positive effect in mass-loss calorimetry, does not lead to such results with the PCFC. More fuels are evolved compared to Epoxy/APP, but they are released at the same temperature range. Carbon nanotubes, which showed an antagonism with APP by mass-loss calorimetry, also release more fuels in the PCFC. Furthermore, it occurs at lower temperature for the material containing CNT and APP than for others. Therefore, there is no relationship between the behaviour of these materials in both fire tests. This has already been established by various authors ${ }^{[23]}$. Indeed, Morgan et al. proposed different hypothesis for the possible absence of correlation between mass-loss calorimetry and PCFC. They pointed out that the sample is not heated in the same way in the two apparatuses and that the sample size is completely different in both testing methods. It is therefore highly probable that the phenomena responsible for the better reaction to fire of Epoxy/APP/POSS in mass-loss calorimetry cannot act similarly in both cases. In the case of intumescent systems, which act through the formation of an insulating layer protecting the underlying polymer, it is not surprising that a thinly grounded material heated in a furnace and weighting only $5 \mathrm{mg}$ cannot behave similarly to the same formulation processed as $5 \mathrm{~mm}$ plates under a cone heater. One of the commonly accepted fact is that PCFC does not correctly measure physical effects ${ }^{[24]}$. Such conclusions are supporting the hypothesis that the main action mechanism of the different systems is acting in the condensed phase. On the contrary, the results reported by Wang et al. ${ }^{[9]}$ showed a synergism between a phosphorus-modified resin and octavinylPOSS measured by PCFC. In that case, the octavinylPOSS more likely reinforces the established gas-phase action of the phosphorus modifier ${ }^{[25]}$.

\section{Thermal stability}

Figure 4 shows the TG curves in air of the different epoxy resin formulations. The volatilization of virgin epoxy occurs in two main steps: a first one between $200^{\circ} \mathrm{C}$ and $430^{\circ} \mathrm{C}$ corresponding to a $60 \%$ weight loss and a second one between $430^{\circ} \mathrm{C}$ and $610^{\circ} \mathrm{C}$ leading to the total volatilization of the resin. The first step corresponds to the decomposition of the epoxy network which results in a char. This char is then oxidized and leads to a further volatilization corresponding to the second volatilization step ${ }^{[26]}$. The incorporation of OMPOSS alone in this system slightly modifies this degradation path. The main volatilization step begins at lower temperatures $\left(160^{\circ} \mathrm{C}\right)$ and the intermediate residue is $20 \mathrm{wt}$.\% lower than that of virgin epoxy. The maximum volatilization rate is however slightly shifted toward higher temperatures. The thermal degradation of OMPOSS has been studied by Fina et al. ${ }^{[22]}$ and Vannier et al. ${ }^{[27]}$. They have shown that this volatilization occurs in a single step between 200 and $350^{\circ} \mathrm{C}$ and 
produces a silica layer. Furthermore, an incomplete sublimation was also noticed. Therefore, it seems that after the initial decomposition onset at lower temperature, the OMPOSS partially shields the epoxy resin. However, this protection is not stable enough and limits the resin charring. The mass loss is thus more important after the first volatilization step. A second step similar to that of virgin epoxy occurs between $500^{\circ} \mathrm{C}$ and $600^{\circ} \mathrm{C}$ leading to the complete polymer volatilization.

When APP is incorporated into the resin, the main volatilization occurs at lower temperatures: the maximum volatilization rate temperature is shifted from $347^{\circ} \mathrm{C}$ to $329^{\circ} \mathrm{C}$ and the intermediate residue is $10 \%$ higher than for virgin epoxy. The volatilization between $460^{\circ} \mathrm{C}$ and $600^{\circ} \mathrm{C}$ remains but it does not lead to the complete volatilization of the resin. A more stable char (20wt\% residue) is produced and a third step is added between 580 and $750^{\circ} \mathrm{C}$. This step corresponds to the final volatilization of the char. One can see how the addition of CNT or OMPOSS modifies the thermal degradation of the Epoxy/APP system. Incorporation of CNT does not have an important effect on the first volatilization step of Epoxy/APP, except that the intermediate residue is 5\% lower. The second volatilization step occurs at slightly higher temperatures and the residues during the last step are lower than that of Epoxy/APP. Concerning the incorporation of OMPOSS, the first volatilization step leads to a $10 \%$ higher intermediate residue. The second volatilization step occurs in the same temperature range as Epoxy/APP and the residues are lower during the last degradation step.

Figure 5 shows the differences between the experimental TGA and the calculated one for each filled epoxy. When the filler is OMPOSS alone, a very small destabilization followed by a similar stabilization occurs between 200 and $300^{\circ} \mathrm{C}$. These phenomena are probably due to the POSS decomposition and/or its sublimation, which causes the initial weight loss and finally produces a silica ceramic layer protecting the residue. Therefore, the underlying material is preserved. The most important stabilization effect $(10 \%)$ occurs between 300 and $400^{\circ} \mathrm{C}$ : the main volatilization step of the epoxy is limited by the presence of the protective silica layer. However, the charring of the epoxy seems disturbed by OMPOSS between 400 and $600^{\circ} \mathrm{C}$ : the weight loss is faster than that of virgin epoxy. The incorporation of APP alone leads to different interactions. First, an important destabilization occurs between 250 and $400^{\circ} \mathrm{C}$. APP decomposes into phosphoric acid, which catalyzes the char formation ${ }^{[28]}$. Supporting this mechanism is the immediate two-step stabilization afterwards, between 400 and $700^{\circ} \mathrm{C}$. When CNT are added to the Epoxy/APP mixture, the weight difference curve follows similar trends as for Epoxy/APP. The initial destabilization is the same but the following stabilization is slightly delayed. Therefore, the antagonism observed during fire tests is confirmed and it seems once more that CNT disturbs the char formation. As a conclusion on the interaction between APP and CNT in epoxy resin, the different tests performed suggest that the material degradation occurs easier when CNT are added to the system. The produced char is also less efficient than for APP alone. Therefore, the material appears unprotected for a longer time, causing the degraded fire behaviour. Finally, incorporation of OMPOSS to Epoxy/APP reveals a less important initial destabilization. Both this destabilization and the following stabilization are shifted towards lower temperatures, respectively 15 and $30^{\circ} \mathrm{C}$. Furthermore, the first stabilization step is stronger than the second one for Epoxy/APP/OMPOSS whereas it is the contrary for the two other intumescent formulations.

\section{CONCLUSION}

In this study, two particles have interacted with the conventional APP in an epoxy resin. Incorporation of CNT along with APP leads to an antagonism in terms of mass-loss calorimetry. The time to ignition is decreased and the peak of heat release rate is increased compared to the resin containing APP alone. PCFC and TGA reveal that the degradation occurs at lower temperatures. On the contrary, partial substitution of OMPOSS by APP strongly enhances the reaction to fire of the material evaluated by mass-loss calorimetry. Moderate effects were identified by TGA, as well as by PCFC. However, qualitative observation of the residual char shows a more resistant structure for Epoxy/APP/OMPOSS than for Epoxy/APP. Furthermore, char cells seem smaller and more regularly 
distributed in Epoxy/APP/OMPOSS. Therefore, it seems that such a modification of the fire properties originates mostly from a physical effect.

\section{AKNOWLEDGEMENTS}

The research leading to these results has received funding from the European Community's Seventh Framework Programme (FP7/2007-2013) under the grant agreement n²13267 - LAYSA "Multifunctional Layers for Safer Aircraft Composites Structures".

\section{REFERENCES}

[1] S. V. Levchik, E. D. Weil, Journal of Fire Sciences 2006, 24, 345.

[2] S. V. Levchik, E. D. Weil, Polymer International 2004, 53, 1901.

[3] M. Zammarano, M. Franceschi, S. Bellayer, J. W. Gilman, S. Meriani, Polymer 2005, 46, 9314.

[4] G. Fontaine, S. Bourbigot, Journal of Applied Polymer Science 2009, 113, 3860.

[5] A. Vannier, S. Duquesne, S. Bourbigot, A. Castrovinci, G. Camino, R. Delobel, Polymer Degradation and Stability 2008, 93, 818.

[6] M. Hussain, R. J. Varley, Z. Mathys, Y. B. Cheng, G. P. Simon, Journal of Applied Polymer Science 2004, 91, 1233.

[7] W. Liu, R. J. Varley, G. P. Simon, Polymer 2007, 48, 2345.

[8] A. Toldy, N. Toth, P. Anna, G. Keglevich, K. Kiss, G. Marosi, Polymers for Advanced Technologies 2006, 17, 778.

[9] X. Wang, Y. Hu, L. Song, W. Xing, H. Lu, Journal of Polymer Science, Part B: Polymer Physics 2010, 48, 693.

[10] S. Bourbigot, S. Duquesne, in Flame Retardant Polymer Nanocomposites (Eds.: A. B. Morgan, C. A. Wilkie), Wiley and Sons, Hoboken, 2007.

[11] S. Bourbigot, S. Duquesne, Journal of Materials Chemistry 2007, 17, 2283.

[12] S. Bourbigot, S. Duquesne, G. Fontaine, S. Bellayer, T. Turf, F. Samyn, Molecular Crystals and Liquid Crystals 2008, 486, 325.

[13] T. Kashiwagi, E. Grulke, J. Hilding, K. Groth, R. Harris, K. Butler, J. Shields, S. Kharchenko, J. Douglas, Polymer 2004, 45, 4227.

[14] T. Kashiwagi, F. Du, K. I. Winey, K. M. Groth, J. R. Shields, S. P. Bellayer, H. Kim, J. F. Douglas, Polymer 2005, $46,471$.

[15] M. Moniruzzaman, K. I. Winey, Macromolecules 2006, 39, 5194.

[16] C. F. Kuan, W. J. Chen, Y. L. Li, C. H. Chen, H. C. Kuan, C. L. Chiang, Journal of Physics and Chemistry of Solids 2010, 71, 539.

[17] S. S. Rahatekar, M. Zammarano, S. Matko, K. K. Koziol, A. H. Windle, M. Nyden, T. Kashiwagi, J. W. Gilman, Polymer Degradation and Stability 2010, 95, 870.

[18] T. Lu, G. Liang, Y. Peng, T. Chen, Journal of Applied Polymer Science 2007, 106, 4117.

[19] Q. Wu, C. Zhang, R. Liang, B. Wang, Journal of Thermal Analysis and Calorimetry 2009, 1.

[20] E. Franchini, J. Galy, J. F. Gérard, D. Tabuani, A. Medici, Polymer Degradation and Stability 2009, 94, 1728.

[21] V. Babrauskas, Journal of Fire Sciences 1986, 4, 148.

[22] A. Fina, D. Tabuani, F. Carniato, A. Frache, E. Boccaleri, G. Camino, Thermochimica Acta 2006, 440, 36.

[23] A. B. Morgan, M. Galaska, Polymers for Advanced Technologies 2008, 19, 530.

[24] B. Schartel, K. H. Pawlowski, R. E. Lyon, Thermochimica Acta 2007, 462, 1.

[25] A. Schäfer, S. Seibold, W. Lohstroh, O. Walter, M. Döring, Journal of Applied Polymer Science 2007, 105, 685.

[26] B. Biswas, B. K. Kandola, A. R. Horrocks, D. Price, Polymer Degradation and Stability 2007, 92, 765.

[27] A. Vannier, S. Duquesne, S. Bourbigot, J. Alongi, G. Camino, R. Delobel, Thermochimica Acta 2009, 495, 155.

[28] G. Camino, M. P. Luda, in Fire Retardancy of Polymers-The use of intumescence, Vol. 224 (Eds.: G. Camino, M. Le Bras, S. Bourbigot, R. Delobel), Royal Society of Chemistry, Cambridge, 1998, p. 48. 
Table 1: Composition of the formulations

\begin{tabular}{cccc}
\hline Epoxy part (wt.\%) & APP (wt.\%) & CNT (wt.\%) & OMPOSS (wt.\%) \\
\hline 100 & - & - & - \\
95 & 5 & - & 5 \\
95 & - & - & - \\
95 & 4.5 & 0.5 & 1 \\
95 & 4 & - & - \\
\hline
\end{tabular}

Table 2: Mass-loss calorimeter main parameters for epoxy formulations (Heat flow: $\left.35 \mathrm{~kW} / \mathrm{m}^{2}\right)(* 0 v e r e s t i m a t e d$ value caused by excessive foaming)

\begin{tabular}{ccccc}
\hline Formulation & $\mathrm{t}_{\text {ign }}(\mathrm{s})$ & $\begin{array}{c}\mathrm{pHRR}\left(\mathrm{kW} / \mathrm{m}^{2}\right) \\
(\% \text { reduction })\end{array}$ & $\begin{array}{c}\mathrm{THR}\left(\mathrm{MJ} / \mathrm{m}^{2}\right) \\
(\% \text { reduction })\end{array}$ & $\begin{array}{c}\text { Residual } \\
\text { weight }(\text { wt. } \%)\end{array}$ \\
\hline Virgin Epoxy & 94 & 1077 & 79 & 0 \\
Epoxy + 5\%APP & 75 & $536(-50)$ & $63(-20)$ & 19 \\
Epoxy + 5\%OMPOSS & 67 & $582(-46)$ & $63(-20)$ & 0 \\
Epoxy + 4\%APP + 1\%OMPOSS & 75 & $326(-68)$ & $90(+14)^{*}$ & 21 \\
Epoxy + 4.5\%APP +0.5\%CNT & 55 & $776(-28)$ & $76(-4)$ & 8
\end{tabular}

Table 3: PCFC main parameters for epoxy formulations (Heating rate: $1^{\circ} \mathrm{C} / \mathrm{s}$ )

\begin{tabular}{ccc}
\hline Formulation & $\begin{array}{c}\text { pHRR }(\text { W/g) } \\
(\% \text { reduction })\end{array}$ & $\begin{array}{c}\text { Temp. @ pHRR } \\
\left({ }^{\circ} \mathrm{C}\right)\end{array}$ \\
\hline Virgin Epoxy & 428 & 357 \\
Epoxy + 5\%APP & $381(-11)$ & 337 \\
Epoxy + 5\%OMPOSS & $419(-2)$ & 355 \\
Epoxy + 4\%APP + 1\%OMPOSS & $414(-3)$ & 337 \\
Epoxy + 4.5\%APP +0.5\%CNT & $410(-4)$ & 318
\end{tabular}




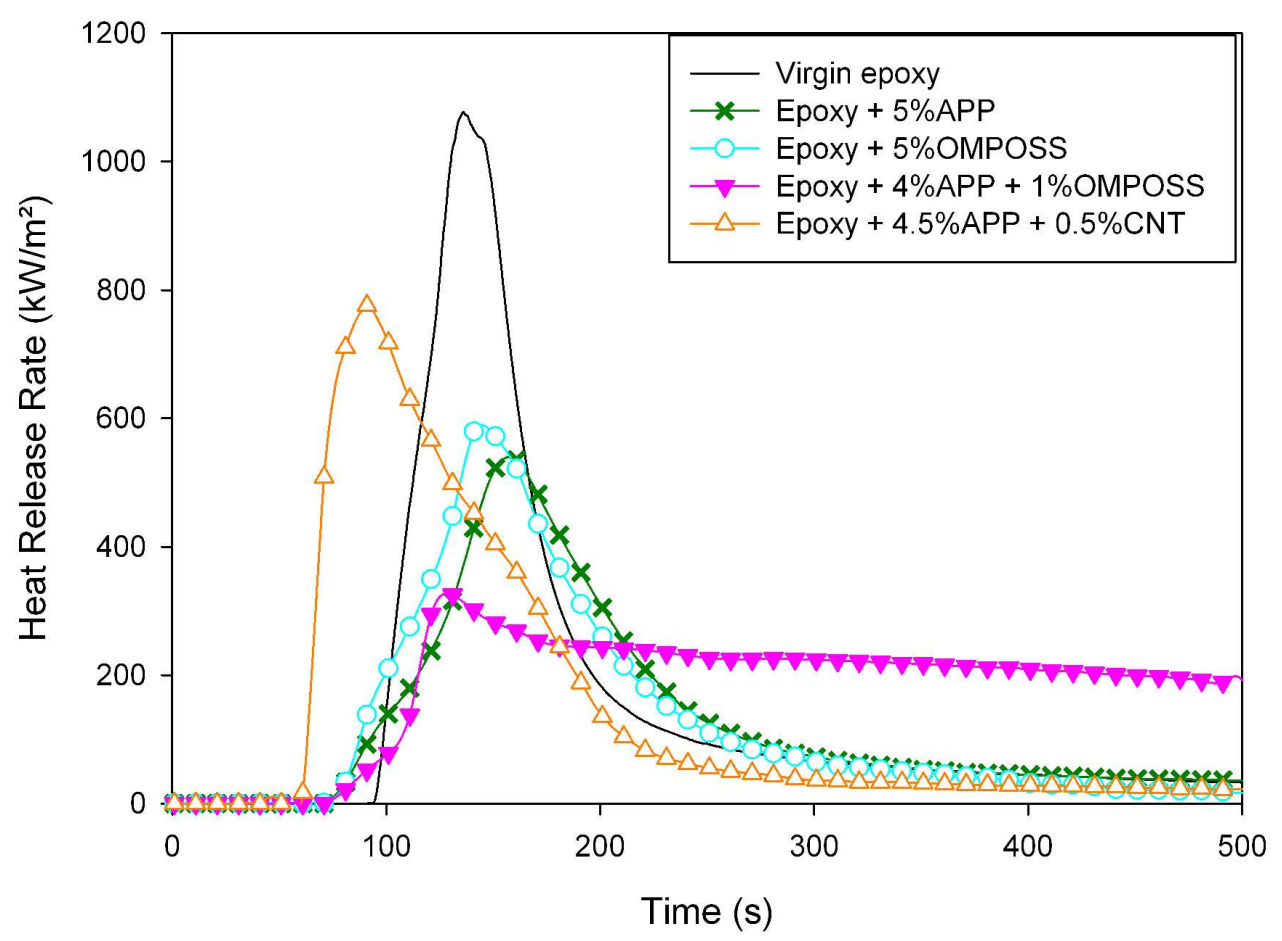

Figure 1: Mass-loss calorimeter curves for epoxy formulations (Heat flux: $35 \mathrm{~kW} / \mathrm{m}^{2}$ ) $151 \times 119 \mathrm{~mm}(600 \times 600 \mathrm{DPI})$ 


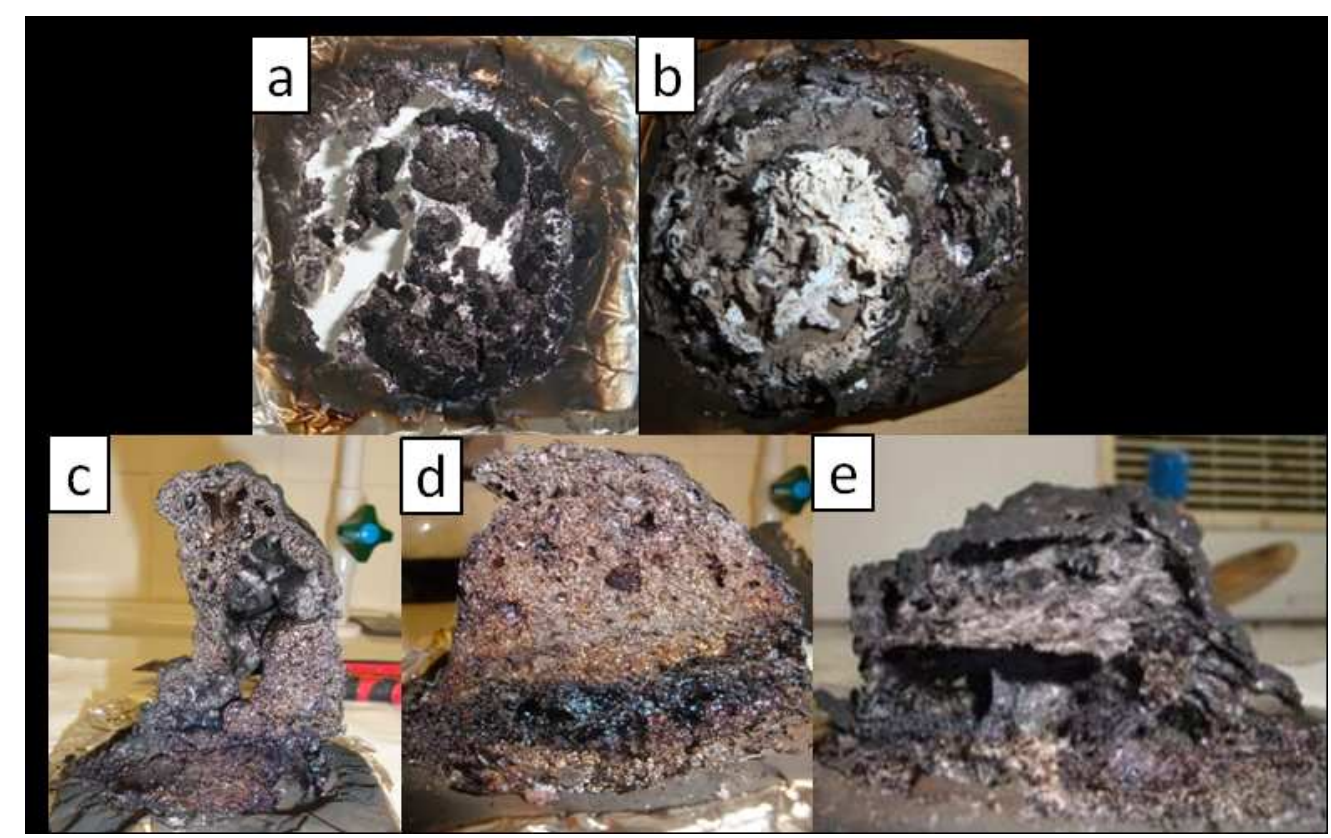

Pictures of the chars obtained after mass-loss calorimeter test (a: virgin (top view), b: 5\%OMPOSS (top view), c: 5\%APP (cross- section), d: 4\%APP-1\%OMPOSS (cross-section), e: $4.5 \%$ APP$0.5 \%$ CNT (cross-section)) $131 \times 82 \mathrm{~mm}(150 \times 150 \mathrm{DPI})$ 


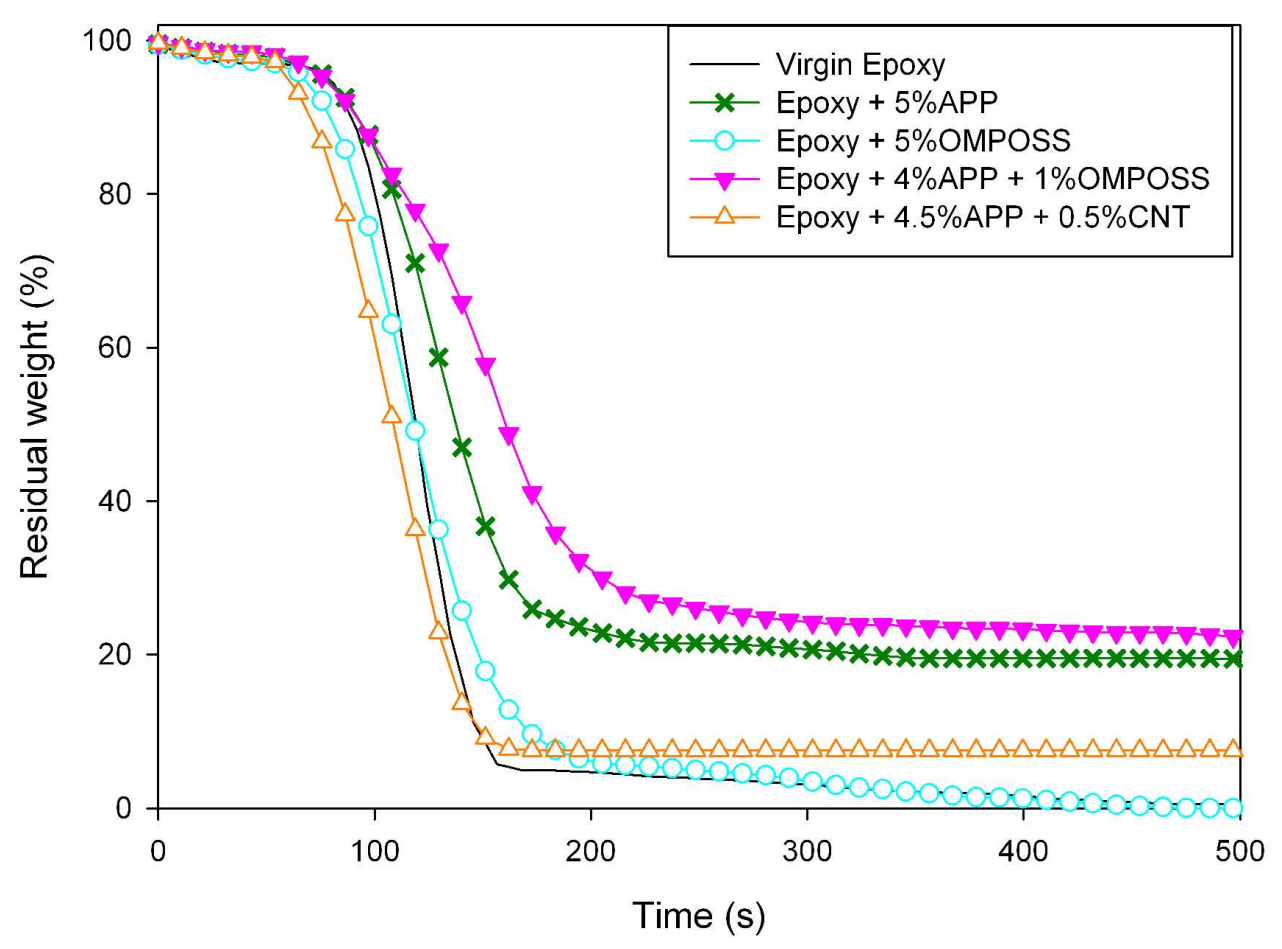

Figure 3: Residual weight versus time for epoxy formulations (Heat flux: $35 \mathrm{~kW} / \mathrm{m}^{2}$ ) $149 \times 119 \mathrm{~mm}(600 \times 600 \mathrm{DPI})$ 


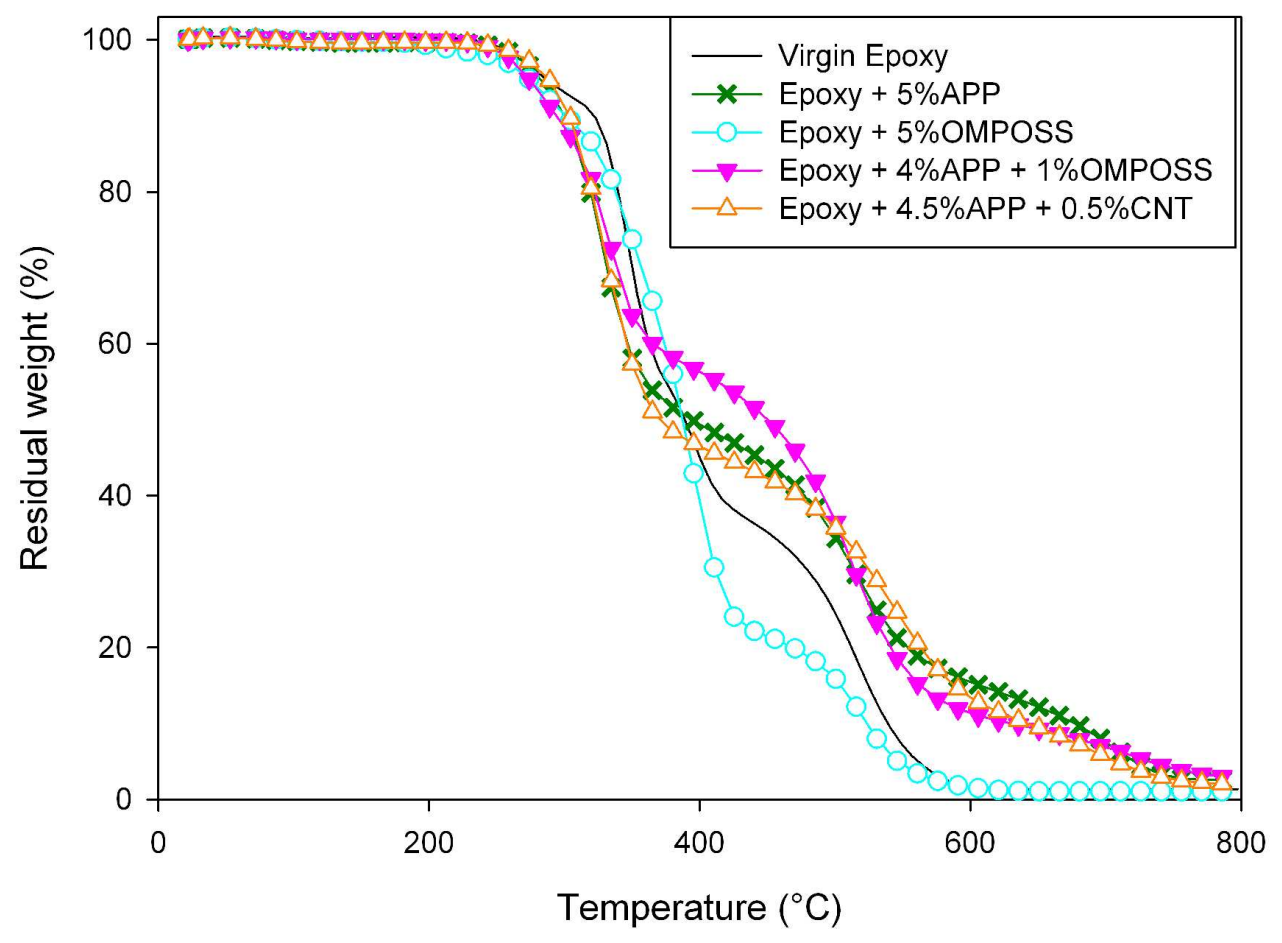

Experimental TGA curves under air of epoxy formulations $149 \times 119 \mathrm{~mm}(600 \times 600$ DPI $)$ 


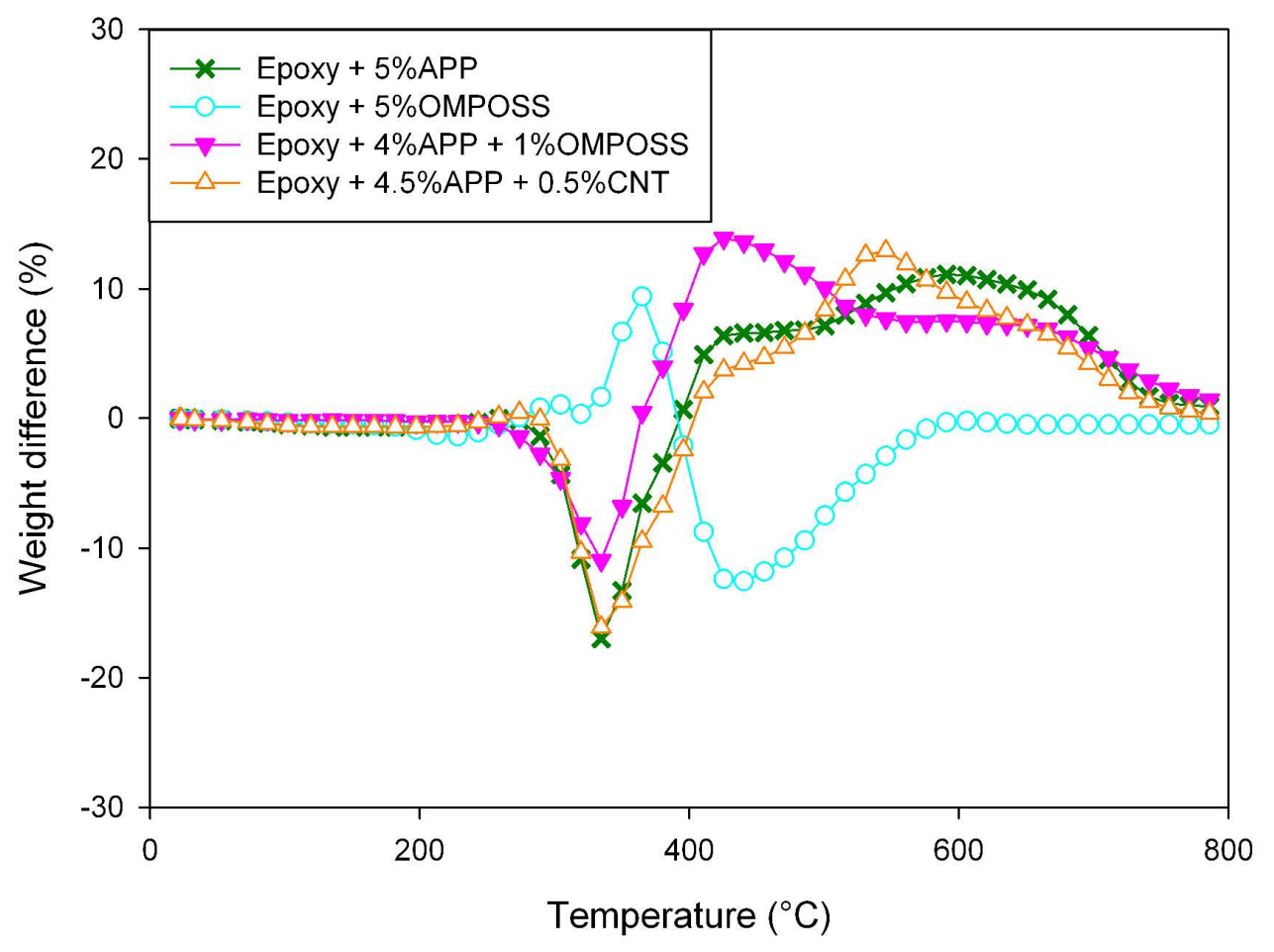

Figure 5: Difference weight curves of theoretical and experimental TGA for epoxy formulations $148 \times 119 \mathrm{~mm}(600 \times 600 \mathrm{DPI})$ 


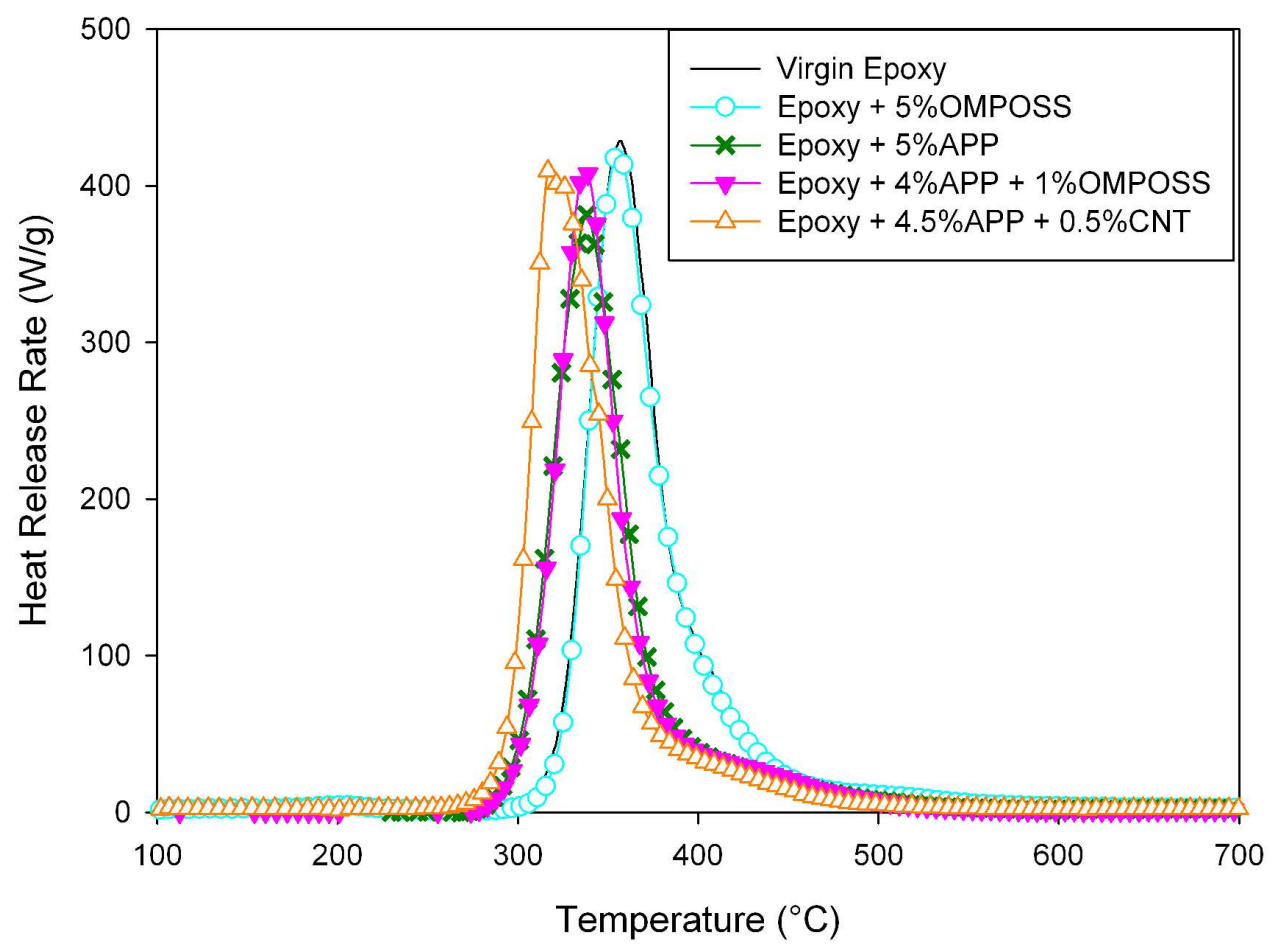

PCFC curves for epoxy formulations $149 \times 119 \mathrm{~mm}(600 \times 600 \mathrm{DPI})$ 